In Memoriam: Ugo Fisch March 3, 1931 to December 12, 2019

Mudry, Albert ; Huber, Alexander

DOI: https://doi.org/10.1097/mao.0000000000002692

Posted at the Zurich Open Repository and Archive, University of Zurich

ZORA URL: https://doi.org/10.5167/uzh-187959

Journal Article

Published Version

Originally published at:

Mudry, Albert; Huber, Alexander (2020). In Memoriam: Ugo Fisch March 3, 1931 to December 12, 2019.

Otology Neurotology, 41(5):574-576.

DOI: https://doi.org/10.1097/mao.0000000000002692 


\section{In Memoriam: Ugo Fisch March 3, 1931 to December 12, 2019}

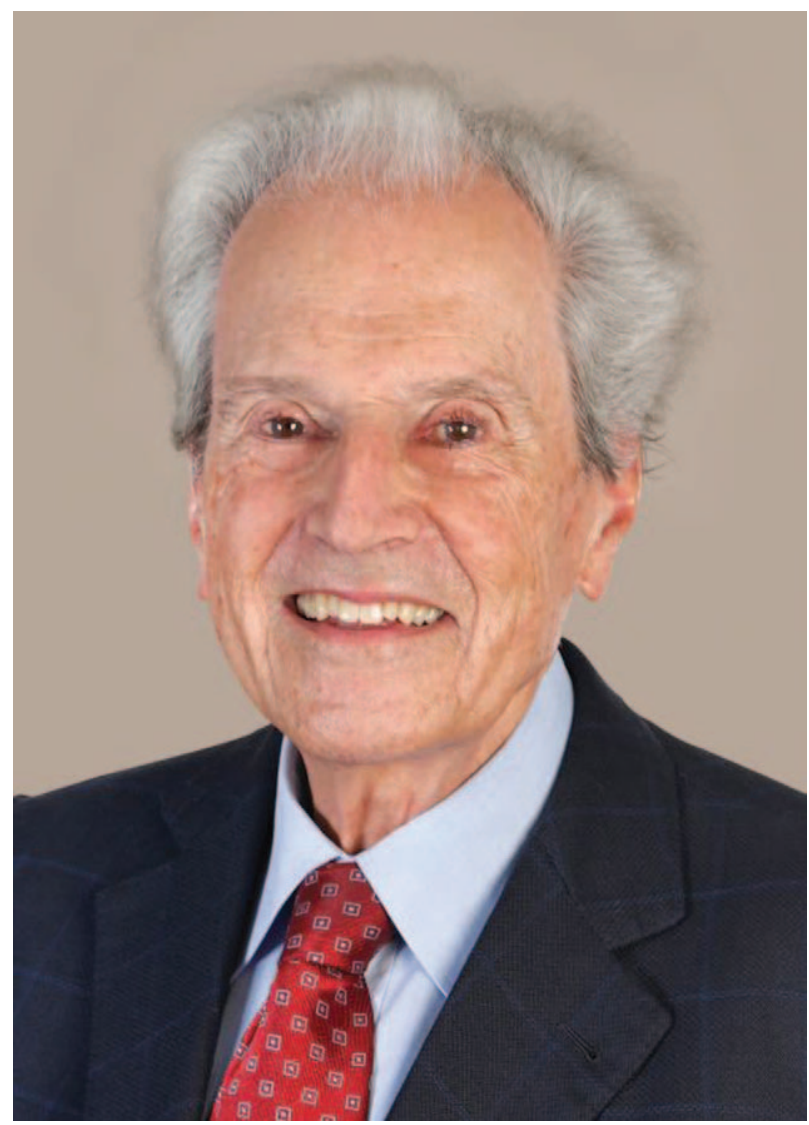

A 1998 editorial in the American Journal of Otology stated, "the more recent extension of otology surgery to include the skull base owes much to such great virtuosos of the temporal bone as Fisch and Sterkers who opened this no man's land to the otologist.'(Magnan J, O'Donoghue G. European Academy of Otology and Neurotology. Am J Otol 1998;19:403-404.)

Born March 3, 1931, in Zug, Switzerland, Ugo Fisch (Fig. 1) moved to Lugano at the age of 2 years after the death of his father. He completed high school there in 1949 after which he began to study medicine at the University of Zurich, where he was graduated in 1955. He commenced his training first in surgery in Winterthur and then in the Otorhinolaryngology (ORL) Department of Zurich under the leadership of Luezius Rüedi. In 1958, Ugo Fisch obtained his doctorate in medicine with his work on thrombosis and diathesis (Über einen neuen Accelerator der Blutthrombokinasebildung). Between
1959 and 1961, he worked as a research fellow in otophysiology at Johns Hopkins University and in the ORL Department of the University of Chicago. After returning to Zurich, he continued his specialized training in ORL. In 1964, he received his specialist title in ORL and married Monica Haas, with whom he had two children, Jann and Marina. In 1966, he was promoted to Associate Professor and received his privatdozent with his research on the lymphographic examinations of the cervical lymphatic system (Lymphographische Untersuchungen über das zervikalen Lymphsystem). In April and May 1967, on the recommendation of Hugo Krayenbühl, Head of Neurosurgery, Zurich University Hospital, he spent 6 weeks at the House Ear Institute in Los Angeles in training with Dr. William House to learn the latest surgical approaches to the internal auditory canal. Upon his return to Zurich, he quickly put his new knowledge into practice and began a fruitful collaboration with the neurosurgeon Gazy Yasargil. In April 1970, he was promoted to Professor of ORL and Head of the ORL Department of the University of Zurich, where he remained until 1999. This new position provided a foundation for Ugo Fisch's career, because it allowed him to develop and teach all of his new microsurgical techniques and to offer them to his patients. In 1998 he founded the Fisch International Microsurgery Foundation with the aim to produce, distribute, and promote exchange of information and multimedia documents of microsurgical ear and skull base procedures for teaching and research purposes. After his academic retirement, he opened a private otology and skull base surgery unit at the ORL Center at Hirslanden Clinic in Zurich in 2000. After complications from a fall in his home, he died in Zurich, December 12, 2019.

As a result of his expertise and widespread influence, Ugo Fisch became an Honorary Member of numerous ORL societies. He received many special awards, notably the Honorary Doctorate of the University of Liège in 1990 and the House/Hitselberger Lifetime Achievement Award of the American Neurotological Society in 2015. Between 2002 and 2004, he was the first president of the newly founded European Academy of Otology \& Neurotology. He has been a member of the editorial boards of such prestigious journals as Annals of Otology, Rhinology \& Laryngology, American Journal of Otology, Otology \& Neurotology, Acta Otorhinolaryngologica (Stockholm), Otolaryngology - Head and Neck Surgery, and Skull Base Journal.

Ugo Fisch was a prolific writer. He published more than 300 papers and three books. Two books were related 
to his microsurgical practice, Tympanoplasty and Stapedectomy published in 1980, which became, in collaboration with Thomas Linder, Tympanoplasty Mastoidectomy and Stapes Surgery in 2008, translated into German, Spanish, Italian, Polish, Chinese, Japanese, and Turkish. The second book, Microsurgery of the Skull Base with Douglas Mattoxwas published in 1988 and translated into German, Spanish, and Chinese. To remember and honor his teachers and mentors, Ugo Fisch finally published, Microscope and Ear, a historical book in collaboration with Albert Mudry and Christoph Mörgeli in 2012, also translated into German, Spanish, and Chinese. The iconagraphic quality of his books was related to his systematic use of videography and operative sketches acquired during his numerous surgeries.

His surgical dexterity and his deep understanding of anatomy and physiology, which was particularly informed by his earlier electrophysiological research, enabled him to break new ground. He further refined and developed the surgical techniques used in ear surgery. Some of these included improvements of the microscopes and drilling systems, standardization of operations for chronic otitis media or his middle ear prostheses that made hearing restoration possible. He was also responsible for the introduction of cochlear implants in Switzerland in 1977. He not only implanted but also designed them together with Thomas Spilmann and Norbert Dillier. Perhaps he is most well known for the development of microsurgical treatments for patients with diseases of the skull base. He notably modified the landmarks for the middle fossa approach, and in 1967 introduced the complete elimination of the pneumatic temporal bone spaces associated with the blind sac closure of the external auditory canal and the permanent occlusion of the Eustachian tube. Subtotal petrosectomy became the essential part of all of Ugo Fisch's approaches, in particular for the transotic approach for acoustic neuroma, which permitted a significant reduction of the risk of postoperative cerebrospinal fluid leak and facial palsy as compared with the translabyrinthine approach of William House. Ugo Fisch also developed three new infratemporal fossa approaches in the 1980s, including the transposition of the intratemporal segment of the facial nerve, to access all intracranial structures surrounding the temporal bone, which attracted global attention. In 1984, he wrote, "Despite the development of a superior (middle cranial fossa) and posterior (translabyrinthine) approach to the temporal bone, tumors situated in the infralabyrinthine and apical compartments of the pyramid and surrounding skull base are still a challenge for neurosurgeons and otolaryngologists as well. The infratemporal approach closes the existing gap in the surgical management of most hidden lesions of the temporal bone." The advances in neuroradiologic imaging and endovascular interventions by his colleague and close friend Anton Valavanis was an integral part of this development. Based on this collaboration, they also introduced the preoperative balloon occlusion of the internal carotid artery in the 1980s, which enabled radical and safe removal of extensive skull base tumors involving the cavernous sinus. Skull base surgery has not only permitted removal of tumors formerly considered as inoperable, but has also broadened the anatomical knowledge of this difficult area so that the surgeon has become familiar with structures like the facial nerve and large arteries and veins supplying the brain that were considered previously too difficult to expose safely. Ugo Fisch definitively demonstrated the ability to control and mobilize these key structures to facilitate visualization and resection of difficult skull base tumors. Through the years, many otologists and neurotologists came from around the world to the ORL Department of Zurich University to learn the basic steps of the microsurgical techniques used for skull base and middle ear surgery. These surgical techniques, which were previously considered impracticable, allowed patients to be treated whose therapy previously seemed hopeless. His techniques are still used worldwide today, and the nomenclature and classification of the infratemporal surgery is based on "Fisch." This made Ugo Fisch and his clinic world famous. Ugo Fisch's dedication and compassion affected both patients, who were referred to him from all over the world and eager fellows who came to his clinic for weeks or months to learn his techniques. The visitor list reads like a Who's Who of Otorhinolaryngology, and many of these former fellows became professors worldwide.

In fact, with his strong sense of clarity and ethics, Ugo Fisch inspired his students and colleagues, including us, not only by his words and teachings but also through his actions. He taught four key conditions for successful ORL medical work: the passion for the work, the philosophy of a structured step-by-step approach or methodology in research, the courage to face the difficult (surgical) problems or academic questions, and always to have the pioneering spirit to search for new possibilities or even impossible tasks. One could learn these lessons from Ugo Fisch every day, and this is what made him an excellent teacher and colleague. We can well remember his lectures, which were always in overcrowded auditoriums. These lectures were clear, exciting, and made one really want to apply the knowledge learned. He never shied away from a dispute and loved answering questions, but also asking them. For his residents and colleagues, even if he came to rounds tired from a long operation, he was still ready to discuss otoscopic findings, confer on radiographs and model how to counsel patients in many different languages. We should point out that even with his compassion, he had no tolerance for answers that were not considered carefully or were incorrect. Anyone who experienced his criticism did not repeat the same mistake twice. As recently as September 2019, during a symposium in Zurich, Ugo Fisch once again made it clear to all of us how to properly conduct a dispute when he disagreed with a well-known international guest speaker. With friendly but unambiguous words and clear-cut arguments, he made the speaker understand what he thought of some of his statements. Ugo Fisch was blessed with a clear and alert mind to the end. That made it even more shocking for all of us that he left life so suddenly. 
Ugo Fisch was also a beloved husband, father, grandfather, and friend. When his long, sometimes very long day was finished, he was nearly always able to spend time with his family and around the family table where his wife Monica had a special place. He was a great admirer of the "petite fleur" of Sydney Bechet and jazz in general, and he used to take time to observe and admire the wonderful landscape in front of his house in Erlenbach and his second house in Vence, southern France. Everyday, even in wintertime, he took a bath in his swimming pool. Eventually, he found the time to paint these landscapes. Despite his busy schedule, he always had a place for his friends, notably enjoying a dinner together.

Ugo Fisch was a pioneer, an empathic doctor, a great university teacher, a unique innovative thinker, and finally, a great man who continually generated ideas in his field throughout his lifetime. May his spirit inspire us forever.

Albert Mudry

Stanford University School of Medicine Palo Alto, CA

Alexander Huber

University Hospital of Zurich

Zurich, Switzerland

alex.huber@usz.ch

The authors disclose no conflicts of interest. DOI: 10.1097/MAO.0000000000002692 